\title{
REDUKSI MISPREPSI PULMONARY EMBOLISM (PE) PADA CT-SCAN ANGIOGRAFI PULMONARY
}

\author{
${ }^{1}$ Ildsa Maulidya Mar'athus N. , ${ }^{2}$ Marjuki \\ ${ }^{1}$ Department of Radiology Universitas 'Aisyiyah Yogyakarta \\ ${ }^{2}$ Instalation Radiology of Moewardi Hospital Surakarta \\ Corresponding Author : Ildsa Maulidya Mar'athus N. \\ e-mail: ildsamaulidya2608@gmail.com
}

\begin{abstract}
Background: Pulmonary Embolism (PE) is the third highest cause of death in cardiovascular. Right ventricular failure usually occurs within the first few hours, leading to the occurrence of right ventricular dysfunction (RVD). Computed tomography pulmonary angiography (CTPA) is an imaging technique that is the gold standard in evaluating patients with suspected PE because of their high sensitivity and specificity. The presentation of Pulmonary CTA images in PE needs to be interpreted correctly so that there is no loss of diagnosis by radiologists and cardiologists. This article aims to find out how to minimize the presence of mispreseption in findings of PE cases using CT-Scan modalities with the CT Pulmonary Angiography protocol.

Methods: The type of research in this mini research is qualitative research with an experimental approach with measurements on the pulmonary arteries that have emboli, which are aimed at knowing the type and evaluating existing parameters to reduce misdiagnosis in PE patients.

Results: The results of identifying the type of emboli using ROI (Region Of Interestand) measurements of the right and left ventricles can be seen that the patient has acute pulmonary embolism. Precise parameter settings play a role in producing informative diagnostic images of Pulmonary CTA.

Conclusion: To obtain informative diagnostic images in cases of pulmonary embolism, it is necessary to pay attention in optimizing the procedures and parameters of pulmonary Angiography CT so that there is no misdiagnosis in patients.
\end{abstract}

Keyword: CT Angio Pulmonary; Pulmonary Emboli; Mesurment Ventricel

\section{Pendahuluan}

Seiring berjalannya waktu beberapa kasus temuan penyakit berdampak pada tingkat kematian populasi manusia di dunia, salah satunya Pulmonary Embolism (PE). PE merupakan penyebab kematian tertinggi ketiga pada kardiovaskular. Ketika PE fatal, kegagalan ventrikel kanan biasanya terjadi dalam beberapa jam pertama, menjadikan terjadinya disfungsi ventrikel kanan (RVD) yang harus didiagnosis dengan cepat dan tepat untuk mengidentifikasi pasien agar dapat dilakukan tindakan yang tepat saat dilakukan terapi fibrinolitik ${ }^{1}$. Pasien dengan emboli paru sering tidak terdeteksi karena gejalanya tidak spesifik dan tidak dapat dicegah. Angka kematian PE berkisar 100.000 hingga 200.000 kematian di Amerika Serikat. Bahkan angka ini dapat bertambah bila tidak ditangani segera $^{2}$. Computed tomography pulmonary angiography (CTPA) merupakan teknik pencitraan yang menjadi gold standar dalam evaluasi pasien dengan dugaan PE karena sensitivitas dan spesifisitasnya yang tinggi ${ }^{3}$. Studi terbaru 
menunjukkan sensitivitas irisan tipis pada MDCTPA menjadi 90-100\% dan spesifisitas menjadi $89-94 \%$ untuk deteksi emboli paru ke tingkat arteri subsegmental, menggunakan angiografi paru sebagai gold standar ${ }^{4}$. CTA paru dalam emboli paru kronis meliputi bukti rekanalisasi, jaringan atau flap, dan cacat pengisian parsial yang membentuk sudut tumpul dengan dinding pembuluh darah. Faktor yang menyebabkan kesalahan diagnosis emboli paru mungkin berhubungan dengan pasien, teknis, anatomi, atau patologis. Dokter radiologi perlu menentukan kualitas dari studi angiografi paru CT dan apakah emboli paru dapat terlihat dengan jelas. Jika citra CTA kurang jelas dalam membantu penegakan diagnosis emboli paru maka dokter radiologi harus melakukan identifikasi arteri paru mana yang tidak terevaluasi dengan baik dan menentukan perlu tidaknya pencitraan tambahan. Sebuah studi baru-baru ini yang mengevaluasi penyebab temuan CTPA tak tentu menemukan tingkat tak tentu $6,6 \%$. Penyebab paling umum adalah artefak gerak pada $74 \%$ kasus; alasan lain termasuk peningkatan yang buruk (40\%), habitus pasien $(7 \%)$, penyakit parenkim (12\%), dan streak artefak. Emboli dapat terlewatkan ketika penyajian citra CTA paru hanya memperlihatkan kontras tinggi saja, yakni pada kasus PE hanya menyajikan pengaturan window mediastinum saja. Pengaturan window yang lebih spesifik pada emboli paru akan membantu membedakan antara sharp margined embolus dengan artefak yang tidak jelas. Namun, pengaturan jendela yang dimodifikasi juga bisa membedakan artefak yang disebabkan oleh noise dan aliran pada citra yang dihasilkan selain itu artefak gerakan pernapasan adalah penyebab paling umum dari CTPA dan dapat menjadi penyebab kesalahan diagnosis emboli paru ${ }^{4}$. Citra CT Angiografi yang dihasilkan akan menentukan treatmen lanjutan yang akan dilakuan oleh dokter ahli jantung berupa oral anticoagulation therapy untuk pembuluh darah vena yang mengalami thomboemboli, treatmen ini memiliki efek apabila tidak diberikan dengan tepat akan meyebabkan perdarahan pada pasien ${ }^{5}$. Radiografer berperan penting dalam menyajikan citra diagnostik pada pemeriksaan CTA paru untuk membantu tim dokter (radiolog dan cardiolog) dalam penegakan diagnosa dengan tepat pada pasien dengan kasus PE sehingga mencegah terjadinya mispreseption.
Artikel ini ditujukan untuk mengetahui cara meminimalisir adanya misspresection pada temuan kasus PE menggunakan modalitas CT-Scan dengan protokol CT Angiografi Pulmonary.

\section{Metode}

Jenis penelitian pada mini riset ini adalah penelitian kualitatif dengan pendekatan eksperimental yang bertujuan untuk mengetahui adanya emboli paru dengan melakukan pengukuran pada pembuluh darah yang mengalami emboli. Pengukuran ini dilakukan agar mendapatkan informasi diagnostik secara tepat dalam menghasilkan citra CTA Pulmonary pada kasus PE yang lebih informative sehingga dapat mengetahui jenis emboli paru yang dialami oleh pasien. Deteksi jenis emboli ini akan membatu pemberian treatmen lanjutan kepada pasien untuk meningkatkan kualitas hidup pasien tersebut.

1 orang pasien dengan pemeriksaan CTA Pulmonary di Instalasi Radilogi RSUD Dr. Moewardi Surakarta sebagai sampel studi terkait. Prosedur dalam studi ini adalah sebagai berikut:

1. Pasien yang didiagnosa PE dilakukan scanning CTA Pulmonary, pertama pembuatan topogram thorax

2. Pemasukan media kontras menggunakan injector

3. Scanning kembali post injeksi media kontras

4. Melakukan reformatting citra yang dihasilkan pada kedua scanning

Salah satu tujuan pemeriksaan CT Angio Pulmnary yang dilakukan di Rumah Sakit Dr. Moewardi Surakarta adalah untuk mengetahui adanya PE baik di arteri maupun vena. Teknik yang dilakakuan secra berurutan dimualai dengan scanning topogram, pre kontras hingga post kontras. Parameter yang digunakan dalam scanning pre dan post kontras antara lain $120 \mathrm{kV}$, $225 \mathrm{mAs}$, dengan scan time 4,5 s, slice thickness rekontruksi $0,5 \mathrm{~mm}$, slice thickness reformart 7 mm, WW: 133, WL: 232. Setelah parameter diatur sedemikanrupa maka scanning dimulai dengan pre kontras terlebih dahulu. Scanning pre kontras didapatkan maka dilakukan triggering pada aorta pulmonary guna menentukan nilai HU yang digunakan untuk penentuan waktu injeksi (bolus trecking). Dilakukan injeksi media kontras secara otomatis dengan konsentrasi 350/100ml dengan 
flowrate 4,5 dan ditambah injeksi menggunakan saline $(\mathrm{NaCl}) 40 \mathrm{ml}$ dengan florwrate 4,5 guna mendorong media kontras masuk kedalam tubuh pasien secara keseluruhan, untuk injeksi media kontras digunakan abocet nomor 18. Setelah itu dilakukan post kontras untuk mendapatkan citra pembuluh darah paru baik arteri maupun vena. Tahapan scanning selesai dilanjutkan dengan proses reformatting citra CTA pulmonary dengan menggunakan MPR. Reformatting citra digunakan untuk mendapatakan beberapa potongan. Potongan yang digunakan untuk mengidentifikasi adanya PE yang dilakuan pada study ini adalah potongan axial dan coronal. Potongan axial ditujukan untuk mengetahui adanya emboli paru pada pembuluh darah arteri, sedangkan pada potongan coronal ditujukan untuk mengetahui adanya emboli pada pembuluh darah vena. Windowing yang digunakan pad mini study ini adalah window mediastinum saja. Penggunaan window mediastinum dirasa sudah dapat menampakkan pembuluh darah arteri maupun vena dengan baik. Sedangkan untuk reformatting citra tidak menggunakan 3D pada pemeriksaan CTA Pulmonary di Rumah Sakit Dr. Moewardi, karena pada potongan axial dan coronal dirasa sudah cukup dalam menampakkan adanya PE.

\section{Hasil dan Pembahasan}

Pada mini research peneliti melakukan beberapa pengukuran pada pembuluh darah paru yang mengalami emboli. Citra yang dihasilkan dari CT Angiografi Pulmonary dilakukan Region of interest (ROI) pada bagian pembuluh darah yang mengalami emboli dengan window mediastinum. Rata-rata yang dihasilkan dari hasil pengukuran ROI digunakan untuk mengukur diameter pembuluh darah yang mengalami emboli. ROI dilakukan pada potongan axial dan coronal. Sehingga dapat diketahui seberapa luas pembuluh darah yang mengalami emboli sehingga dapat membantu dalam penegakan diagnose dan treatmen lanjutan pada pasien emboli. Hasil pengukuran ROI potongan axial pada penelitian ini menunjukan angka mean 150,3 dengan nilai SD 120,3. Sedangkan pengukuran venntrikel kanan dan kiri menunjukan nilai $36,5 \mathrm{~mm}$ ventrikel kanan dan $34,3 \mathrm{~mm}$ pada ventrikel kiri.

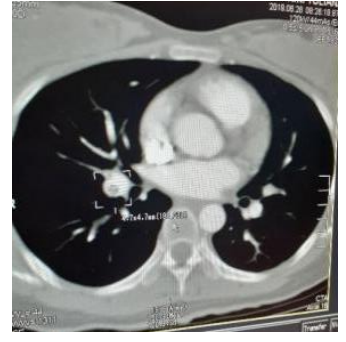

(a)

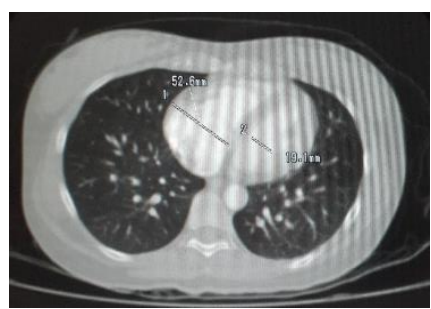

(b)
Gambar 1. (a) ROI pada potongan axial kasus PE. (b) Pengukuran pada potongan axial ventrikel kanan dan kiri pada pasien kasus PE.

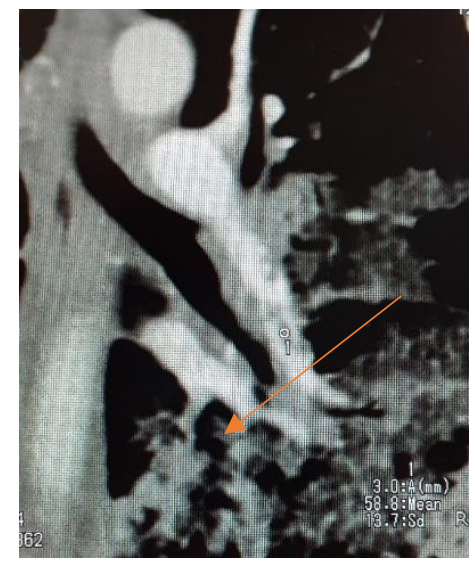

Gambar 2. ROI potongan coronal emboli paru

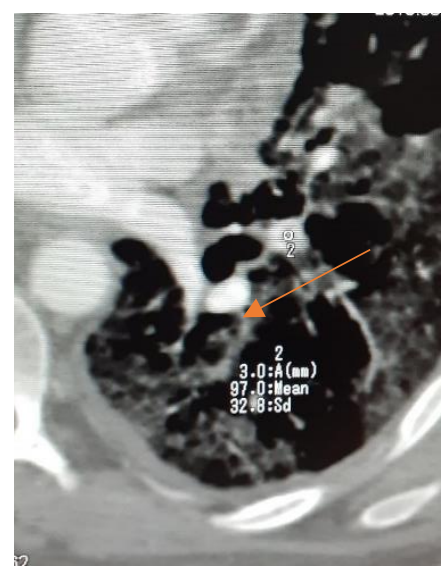

Gambar 3. ROI potongan axial emboli paru 


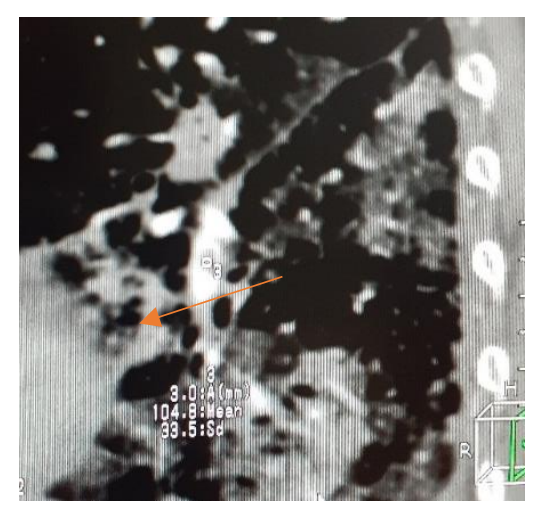

Gambar 4. ROI potongan sagittal emboli paru.

Pengukuran diameter pembuluh darah dengan melakukan ROI pada pembuluh darah yang mengalami emboli dengan teknik pemeriksaan CTScan Angiografi Pulmonary. Pengukuran hanya dilakukan post contrast injection pada diameter pembuluh darah yang mengalami emboli saja, namun peneliti tidak melakukan ROI pada daerah disekitar pembuluh darah yang tidak mengalami emboli paru sehingga tidak dapat mengetahui secara pasti emboli yang diderita pasien apakah emboli akut ataupun kronis. Meaney et al. menyatakan bahwa deteksi kelainan kontras rendah tidak akurat ketika SD dari rata-rata kelainan melebihi perbedaan dalam rata-rata lesi dan daerah sekitarnya. Untuk emboli paru akut, atenuasi rata-rata nilai adalah $33 \mathrm{H}^{6}$. Hal tersebut sebenarnya dapat membantu penentuan dokter dalam mendiagnosa adanya emboli yang dialami oleh pasien merupakan emboli akut maupun kronik. Penyebab dari kedua jenis emboli tersebut disebabkan karena intraluminal filling defects yang akan tampak tajam pada permukaan dengan pengijeksian media kontras intravena. Namun dibeberapa kasus pasien yang mengalami emboli paru sering terlewatkan dikarenakan emboli paru di arteri subsegmental sering tidak terdeteksi ${ }^{7}$. Selain menggunakan ROI untuk mengetahui emboli akut atupun kronis dapat dilakukan pengukuran terhadap ventrikel baik sebelah kanan maupun kiri. Dari pengukuran sumbu axis pada kedua ventrikel diketahui bahwa ventrikel kanan lebih luas dibandingkan dengan ventrikel kiri, hal tersebut dapat dinyatakan bahwa pasien menderita akut emboli paru. Conrad Wittram dalam penelitiannya menyatakan bawah adanya akut emboli paru dapat diketahui dengan pengukuran terhadap ventrikel kanan maupun kiri. Apabila salah satu ventrikel mengalami perluasan yang signifikan maka dapat diketakan bahawa pasien tersebut mengalami akut emboli paru. Untuk mendapatkan adanya gambaran emboli pada paru secara akurat sebaiknya mengatur parameter dengan tepat pada pemeriksaan CTA Pulmonary, sedangkan kronik PE dapat diidentifikasi dengan gambaran CT-Sscan menunjukkan pembesaran atau pelebaran pada arteri pulmonalis kiri. Sedangkan protocol yang dainjurkan menggunakan window mediastinum (400/40) dan untuk mendapatkan PE secara spesifik menggunakan (700/100), dengan pengaturan window width/level( $1500 / 600)^{7}$. Pada study ini menggunakan HU 180 dengan menggunakan window mediastinum. Pada dasarnya untuk menentukan adanya PE tidak dapat menggunakan WW dan WL dengan nilai tertentu sebagai tolak dalam menampakkan suatu emboli, karena setiap alat memiliki ketentuan yang berbedabeda karena window akan mempengaruhi visualisasi, sehingga dapat menampilkan perbedaan vaskuler yang terisi media kontras dengan adanya plak pada citra yang dihasilkan. Pada citra post kontras apabila terdapat plak dengan mengatur windowing secara tepat maka opasitas pada vaskuler akan memiliki tampilan enhacement yang tinggi.

Adanya fenomena dalam pengaturan windowing tersebut menuntut radiografer untuk memperhatikan aspek lain dalam menghasilkan citra dengan patologi PE yakni dengan menetukan ketepatan vase akuisisi/scanning. Biasanya vase arteri dapat digunakan sebagai acuan untuk mendapatkan ketepatan scanning. Untuk mendapatkan ketepatan dalam vase arteri dapat dilakukan dengan monitoring auto TICAR menggunakan CT Number (HU) dengan melakukan ROI setinggi pada arteri pulmonalis.

Namun pada study ini ROI tidak cukup membantu dalam menampakkan seberapa luas PE yang terjadi pada pembuluh darah pasien, perlu dilakukan teknik tambahan, karena pada kasus PE, dapat terjadi perluasan pembuluh darah yang mengalami emboli, perluasan inilah yang perlu dipastikan hingga mana karena akan membantu dokter dalam melakukan suatu treatment pada pasien. Menggunakan ROI saja tak mampu menampakan perluasan tersbut dengan jelas, maka diperlukan suatu inofasi tambahan untuk mengetahui seberapa luas emboli yang terjadi pada pasien. Perlu dilakukan study lanjutan dalam menentukan perluasan pembuluh darah yang mengalami emboli.

Selain itu untuk mendiagnosis suatu emboli paru pada pasien dengan mengoptimalkan parameter, adanya artefak yang dapat menyebabkan misdiagnosis. Artefak yang sering muncul pada saat pemeriksaan CTA Pulonary antara lain motion 
artefak yang disebabkan pergerakan pasien saat bernafas, untuk mengatasi artefak ini dapat menggunakan CT multiseksi tingkat tinggi, yang membutuhkan napas lebih pendek. Beam-hardening artifacts yang disebabkan oleh pemasangan artery catheter pada pasien yang mengalami kritis, artefak ini dapat menyebabkan kesalahan diagnostik karena pada beam-harding artefak dapat meniru karaktersitik dari emboli paru sendiri.

\section{Simpulan}

Untuk mendapatkan citra diagnostik yang informatif pada kasus emboli paru perlu diperhatikan dalam mengoptimalkan prosedur dan parameter CT Angiografi Paru sehingga tidak terjadi misdiagnosis pada pasien,

\section{Daftar Pustaka}

1. Forces A, Southern H, Mushayt K, Arabia S. Prediction of pulmonary embolism outcome and severity by computed tomography. 2010;

2. Lubis B, Nasution AH, Magdalena B, Purwaamidjaja DB. Peran Angiografi Pada Emboli Paru. X:16-21.

3. Roos A De, Huisman PDM V, Ph D. Imaging Tests in the Diagnosis of Pulmonary Embolism. 2012:138-143.

4. Wittram C. How I Do It: CT Pulmonary. 2007;(May)

5. Hutchinson BD, Navin P, Marom EM, et al. Overdiagnosis of Pulmonary Embolism by Pulmonary. 2015;(August):271-277.

6. Meaney F, Raudkivi U, Mcintyre WJ, et al. Detection of LowContrast Lesions in Computed Body Tomography : An.

7. Wittram C, Maher MM, Yoo AJ, Kalra MK, Shepard J-AO, McLoud TC. CT Angiography of Pulmonary Embolism: Diagnostic Criteria and Causes of Misdiagnosis. RadioGraphics. 2004;24 